\title{
Direct bonding of AIN and graphite by spark plasma sintering
}

\author{
Tomoyuki OKUNI, ${ }^{*, *}$ Yoshinari MIYAMOTo, ${ }^{*, *, \dagger}$ Hiroya ABE ${ }^{* *}$ and Makio NAITO** \\ *Advanced Carbon Technology Center, Toyo Tanso Co., Ltd., 5-7-12 Takeshima, Nishiyodogawa-ku, Osaka 555-0011, Japan \\ ** Joining and Welding Research Institute, Osaka University, 11-1 Mihogaoka, Ibaraki, Osaka 567-0047, Japan
}

\begin{abstract}
AIN powders were simultaneously sintered and bonded to isotropic graphite disks at temperatures of 1800 and $1900^{\circ} \mathrm{C}$ under $30 \mathrm{MPa}$ by spark plasma sintering (SPS). The effects of temperature and $\mathrm{Y}_{2} \mathrm{O}_{3}$ additive content on the bonding strength were investigated. The bonding mechanism is proposed as follows: as the temperature increases, a molten Al-Y-O phase forms and flows into the open pores of graphite. As the material cools, a $\mathrm{Al}_{2} \mathrm{Y}_{4} \mathrm{O}_{9}$ phase forms, resulting in a physical bond between the graphite and AIN. The bonding strength of AIN/graphite increased with an increase of temperature and $\mathrm{Y}_{2} \mathrm{O}_{3}$ content. When 10 mass \% $\mathrm{Y}_{2} \mathrm{O}_{3}$ was used as a sintering additive, the bonding strength of AIN/graphite reached $19 \mathrm{MPa}$ at $1900^{\circ} \mathrm{C}$.
\end{abstract}

(C2013 The Ceramic Society of Japan. All rights reserved.

Key-words : Aluminum nitride, Graphite, Bonding, Spark plasma sintering

[Received December 27, 2012; Accepted April 14, 2013]

\section{Introduction}

High-density isotropic graphite has high temperature resistance, excellent thermal shock and chemical resistance, adding to its self-lubricating and light weight. These properties make it suitable for many applications, including crucibles and heaters used for silicon semiconductor manufacturing, continuous casting dies, electrodes for electric discharge machining, and other industrial applications. However, graphite has a lower mechanical strength than ceramics and metals at room temperature. In addition, it cannot be used with certain metals at high temperatures, including iron, cobalt, titanium, and tungsten because carbon atoms diffuse into these metals. When this diffusion occurs, the melting temperatures are reduced and the metals react with graphite to form carbides.

Studies have shown that coating graphite with carbide ceramics, such as $\mathrm{SiC}$ and $\mathrm{B}_{4} \mathrm{C}$, can improve oxidation resistance. ${ }^{1)-3)}$ However, few studies have reported on the bonding of graphite with nitride ceramics, such as AlN. Such bonding between AlN and graphite is of importance in its applications such as heat sinks and heating trays for metals because AlN has both a high electric insulation and thermal conductivity. It can prevent carbon diffusion into metals at high temperature as well.

Spark plasma sintering (SPS) is an efficient process to sinter ceramics and metals. ${ }^{4-8)}$ It is also used for joining of dissimilar ceramics or metals, and ceramic-to-metal combinations. For example, Kondo et al. reported that stacked powders of TiN and apatite were sintered and simultaneously joined by SPS. ${ }^{9)}$ A functionally graded alumina-carbon nanotube system consisting of four alumina layers with different concentrations of carbon nanotubes has also been fabricated by SPS. ${ }^{10)}$

In this study, SPS was successfully used to bond graphite and AlN together without any interlayer. The effect of $\mathrm{Y}_{2} \mathrm{O}_{3}$ additive and heating temperature on the bonding strength was investigated, and the bonding mechanism was discussed.

$\uparrow$ Corresponding author: Y. Miyamoto; E-mail: miyamoto@jwri. osaka-u.ac.jp

\section{Experimental procedure}

AlN powder (H-grade, Tokuyama Co. Ltd.,) with a particle size of $1 \mu \mathrm{m}$ and $\mathrm{Y}_{2} \mathrm{O}_{3}$ powder (particle size $=1 \mu \mathrm{m}$, RU-P, Shin-Etsu Chemical Co., Ltd.) as a sintering additive were used as starting materials. Isotropic graphite disks (IG-12, Toyotanso Co., Ltd.) of 25-mm diameter and 4-mm thickness were used for the bonding with AIN. The physical properties are listed in Table 1. It has been used in many conventional applications. The relative density is $79 \%$ of the theoretical density $\left(2.25 \mathrm{Mg} / \mathrm{m}^{3}\right)$. The coefficient of thermal expansion (CTE) is $4.7 \times 10^{-6} / \mathrm{K}$, which is similar to that of AlN $\left(4.5 \times 10^{-6} / \mathrm{K}\right){ }^{11)}$ AlN powder was mixed with $\mathrm{Y}_{2} \mathrm{O}_{3}$ of different mass ratios of $0,2.5,5.0$, and $10 \%$ by using a planetary centrifugal mixer (ARE-310, Thinky Corporation). The mixed powder $(1.8 \mathrm{~g})$ was placed on top and beneath the graphite disk in a graphite die with an inner diameter of $25 \mathrm{~mm}$, as illustrated in Fig. 1. Graphite sheets of $500-\mu \mathrm{m}$ thickness (PF-50, Toyotanso Co., Ltd.) were placed between the bonded sample and graphite punches. The sintering and bonding were simultaneously carried out at temperatures from 1700 to $1900^{\circ} \mathrm{C}$ under $30 \mathrm{MPa}$ for $5 \mathrm{~min}$ under vacuum by SPS (SPS1050, Sumitomo Coal Mining Co., Ltd.). The bonding temperature was measured by focusing a pyrometer into a hole with $1 \mathrm{~mm}$ diameter made at the side of the die.

The sandwich-type samples of AlN/graphite were ground and polished to a size of $25-\mathrm{mm}$ diameter $\times 6$-mm thickness, and then cut into test bars of 4-mm in width $\times 4-\mathrm{mm}$ in length $\times 6-\mathrm{mm}$ in height for measuring bonding strength. The microstructure observation and elemental analysis of these samples were also performed by scanning electron microscopy-energy dispersive X-ray spectroscopy (SEM-EDS, ERA-8800FE, ELIONIX Co.,

Table 1. Physical properties of isotropic graphite used in the present study

\begin{tabular}{ccccc}
\hline $\begin{array}{c}\text { Raw } \\
\text { material }\end{array}$ & $\begin{array}{c}\text { Bulk density } \\
\left(\mathrm{Mg} / \mathrm{m}^{3}\right)\end{array}$ & $\begin{array}{c}\text { Relative density } \\
(\%)\end{array}$ & $\begin{array}{c}\text { Tensile strength } \\
(\mathrm{MPa})\end{array}$ & $\begin{array}{c}\mathrm{CTE} \\
\left(10^{-6} / \mathrm{K}\right)\end{array}$ \\
\hline $\begin{array}{c}\text { Isotropic } \\
\text { graphite }\end{array}$ & 1.78 & 79 & 28 & 4.7 \\
\hline
\end{tabular}




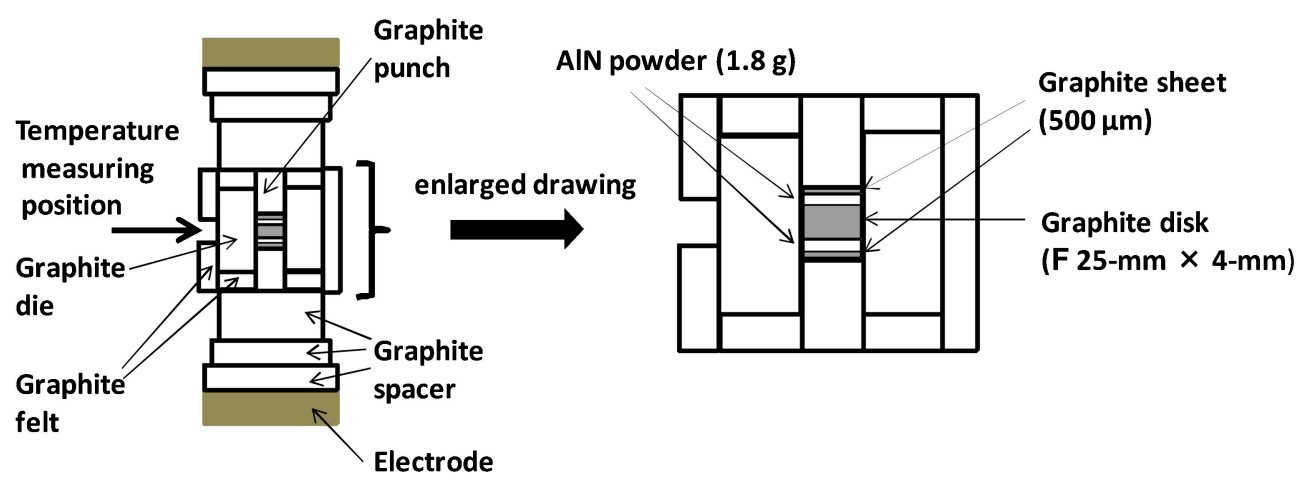

Fig. 1. SPS setup to make bonding between AIN and graphite.

Table 2. Bonding strength of the AlN/graphite samples in relation to the amount of sintering additive

\begin{tabular}{cc}
\hline $\begin{array}{c}\text { Amount of } \mathrm{Y}_{2} \mathrm{O}_{3} \\
(\text { mass \%) }\end{array}$ & Bonding strength $(\mathrm{MPa})$ \\
\cline { 2 - 2 } 0 & $1900^{\circ} \mathrm{C}$ \\
2.5 & $3(3)$ \\
5 & $9(6)$ \\
10 & $13(4)$ \\
\end{tabular}

Numbers in parentheses denote the standard deviation of bonding strength.
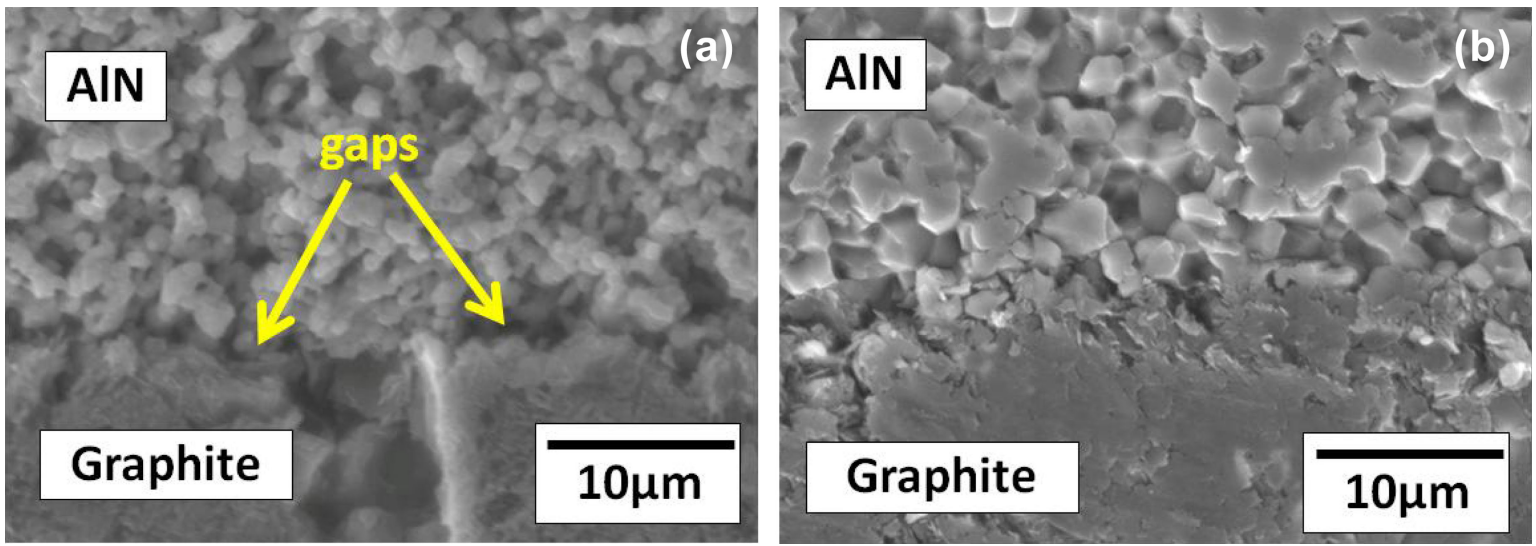

Fig. 3. Cross-sectional SEM image at the interface of the $\mathrm{AlN} /$ graphite samples prepared at (a) $1700^{\circ} \mathrm{C}$, and (b) $1900^{\circ} \mathrm{C}$ with 5 masss $\% \mathrm{Y}_{2} \mathrm{O}_{3}$ additive.

LTD). Crystalline phases were examined by X-ray diffraction (XRD, Ultima IV, Rigaku Corporation). Bonding strength of AlN/graphite samples was measured by tensile testing (EZ-L, Shimadzu Corporation). Figure 2 shows a schematic drawing of jigs used for measuring the bonding strength. Stainless steel jigs were adhered to the top and bottom of seven AlN/graphite samples using an epoxy resin adhesive (E-60HP, Henkel AG \& Co. $\mathrm{KGaA}$ ) at $80^{\circ} \mathrm{C}$ for about $24 \mathrm{~h}$ and subjected to tensile testing.

\section{Results and discussion}

\subsection{Effect of heating temperature on bonding}

Figure 3 shows the interface of the $\mathrm{AIN}\left(5\right.$ mass $\left.\% \mathrm{Y}_{2} \mathrm{O}_{3}\right) /$ graphite samples prepared at $1700^{\circ} \mathrm{C}$ (a) and at $1900^{\circ} \mathrm{C}$ (b). In the $\mathrm{AlN} /$ graphite samples prepared at $1700^{\circ} \mathrm{C}$, some gaps are observed at the AlN/graphite interface. The grain growth of AlN does not developed, resulting in low density of AlN layer. This

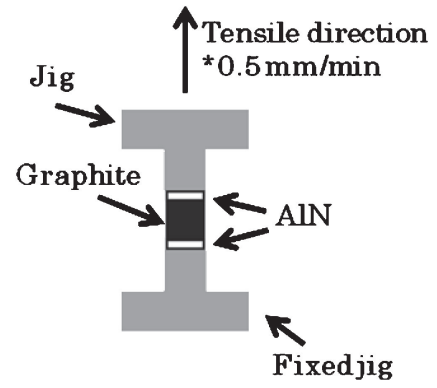

Fig. 2. Schematic drawing of jigs used for measuring bonding strength. sample is easily separated by hand. In contrast, AlN and graphite were tightly bonded at $1900^{\circ} \mathrm{C}$. As seen in Fig. 3(b), no gaps and delaminations are observed at the interface. Grain growth occurs and the AlN sintered layer is densified.

Figure 4 shows the SEM images and elemental analysis of $\mathrm{C}, \mathrm{Al}$, and $\mathrm{Y}$ at the bonding interface at different temperatures of 1700 and $1900^{\circ} \mathrm{C}$. Yttrium is distributed only in the sintered AlN layer of the sample when prepared at $1700^{\circ} \mathrm{C}$. For the sample prepared at $1900^{\circ} \mathrm{C}$, there was little $\mathrm{Y}$ found in the AlN layer, but a high concentration was found in the graphite disk. A similar Y distribution in graphite was observed in the sample prepared at $1800^{\circ} \mathrm{C}$, although it is not shown here.

During sintering of AlN with $\mathrm{Y}_{2} \mathrm{O}_{3}$, a liquid phase of the Al$\mathrm{Y}-\mathrm{O}$ system forms at around $1800^{\circ} \mathrm{C}^{12)}$ and solidifies as a grain boundary phase during cooling. Since the graphite disk used in this study has an open porosity over $10 \%$, it is believed that the 


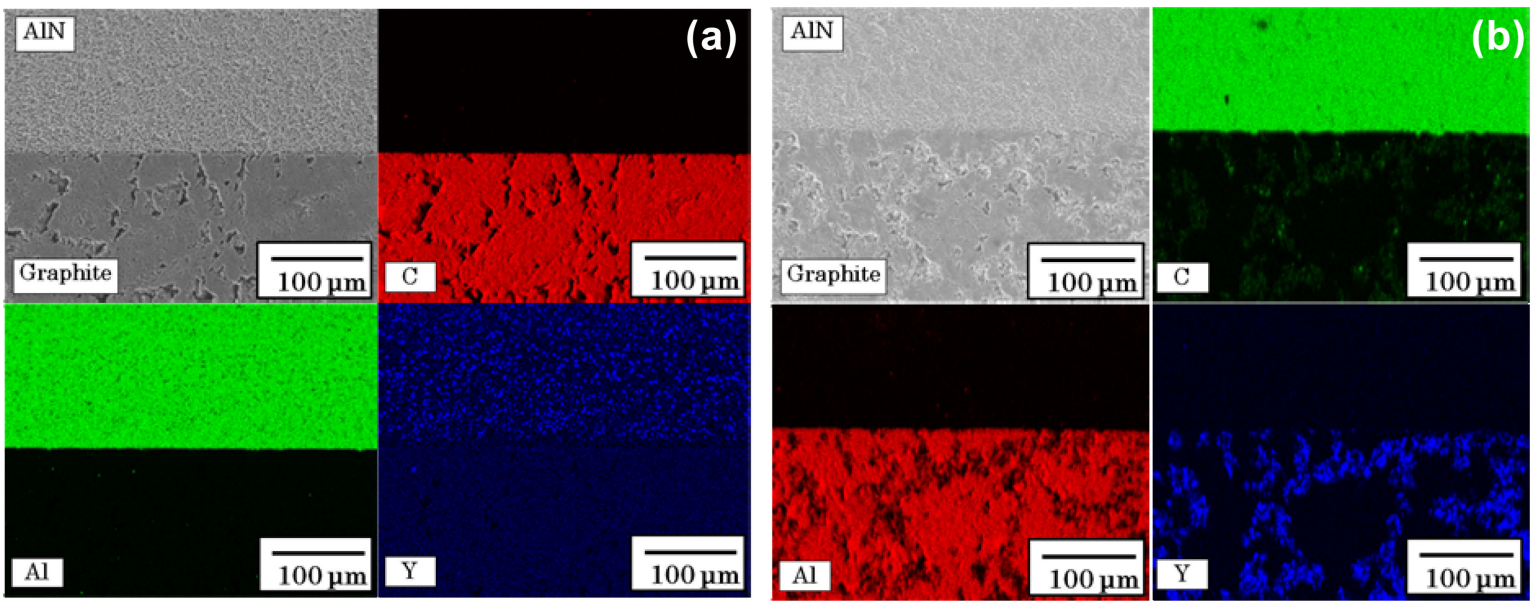

Fig. 4. Cross-sectional SEM images and elemental mapping images of $\mathrm{C}, \mathrm{Al}$, and $\mathrm{Y}$ at the interface of the AlN/graphite samples prepared at (a) $1700^{\circ} \mathrm{C}$, and (b) $1900^{\circ} \mathrm{C}$ with 5 mass $\% \mathrm{Y}_{2} \mathrm{O}_{3}$ additive.

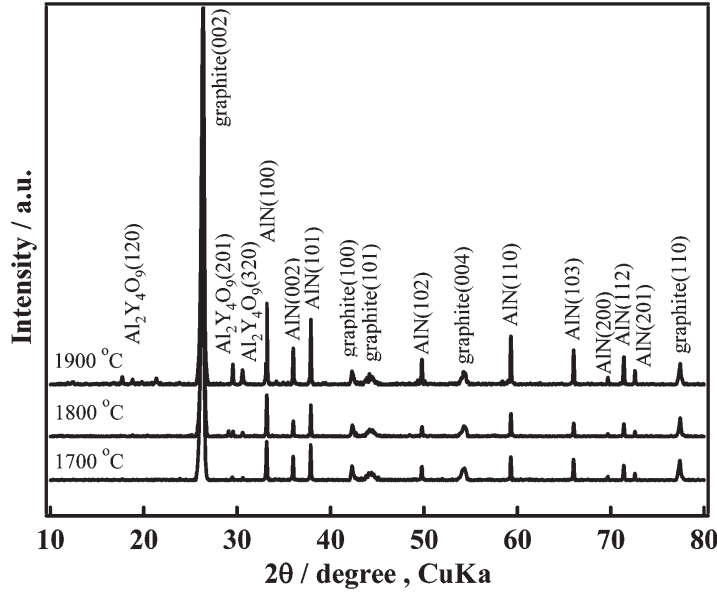

Fig. 5. Change in XRD patterns of the AlN/graphite samples prepared at different temperatures.

liquid phase of $\mathrm{Al}-\mathrm{Y}-\mathrm{O}$ flows into the open pores under the external pressure of $30 \mathrm{MPa}$ during SPS.

Figure 5 shows the change in XRD patterns at the interface of the AlN/graphite samples prepared at different temperatures. The crystalline phase of $\mathrm{Al}_{2} \mathrm{Y}_{4} \mathrm{O}_{9}$ solidifies from the $\mathrm{Al}-\mathrm{Y}-\mathrm{O}$ melt during cooling. Because no chemical reaction occurs between AlN and graphite, the bonding is of a physical type. In other words, the molten $\mathrm{Al}-\mathrm{Y}-\mathrm{O}$ phase fills into gaps at the interface and flows into open pores located at the surface of the graphite disk at temperatures over $1800^{\circ} \mathrm{C}$.

Figure 6 shows the average bonding strength as a function of bonding temperature. The bonding strength increases sharply above $1800^{\circ} \mathrm{C}$, at which the $\mathrm{Al}-\mathrm{Y}-\mathrm{O}$ phase penetrates into the graphite. The AlN/graphite sample prepared at $1900^{\circ} \mathrm{C}$ shows a high strength of $13 \mathrm{MPa}$. The viscosity of the molten Al-Y-O phase decreases with an increase in bonding temperature. Thus, the $\mathrm{Al}-\mathrm{Y}-\mathrm{O}$ phase flows easily into the graphite pores. During cooling, a strong bond forms between the sintered AIN layer and graphite.

\subsection{Effect of $\mathrm{Y}_{2} \mathrm{O}_{3}$ content on bonding}

In order to understand the effect of the sintering additive, the content of $\mathrm{Y}_{2} \mathrm{O}_{3}$ was increased from 0 to 10 mass $\%$ for the bonding at $1900^{\circ} \mathrm{C}$. Figure 7 shows the relationship between the

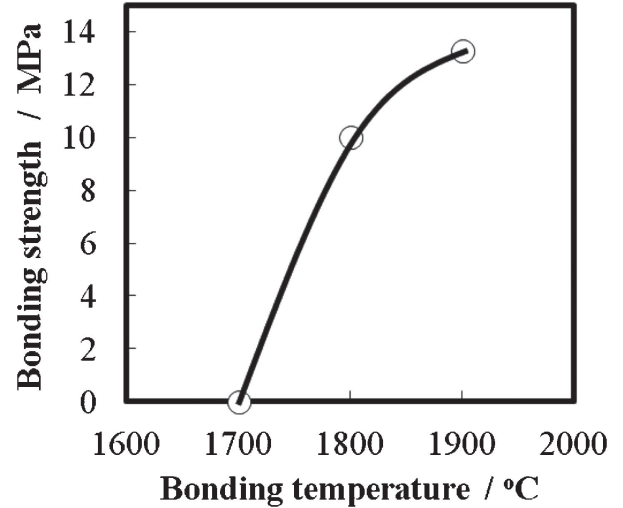

Fig. 6. Bonding strength of AlN/graphite samples as a function of heating temperature.

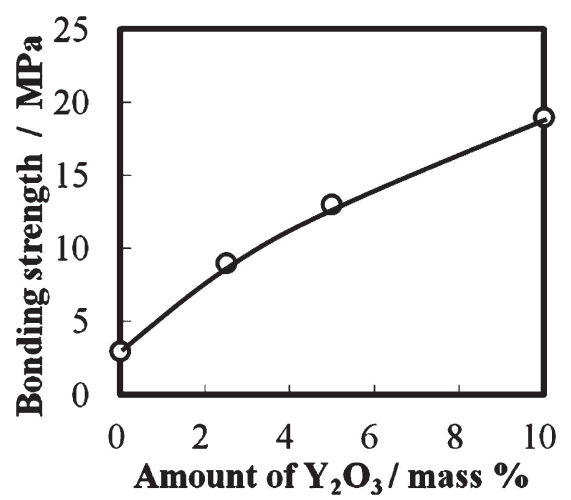

Fig. 7. The relationship between bonding strength of $\mathrm{AlN} /$ graphite samples and the amount of $\mathrm{Y}_{2} \mathrm{O}_{3}$ additive.

average bonding strength and the $\mathrm{Y}_{2} \mathrm{O}_{3}$ content. The strength increases from 3 to $19 \mathrm{MPa}$ by adding 10 mass $\% \mathrm{Y}_{2} \mathrm{O}_{3}$. In the AlN/graphite sample containing no $\mathrm{Y}_{2} \mathrm{O}_{3}$, the joint failed at the interface during tensile testing. In the sample containing $\mathrm{Y}_{2} \mathrm{O}_{3}$, the joint failed in the graphite near the interface. Since the tensile strength of graphite is $28 \mathrm{MPa}$ as listed in Table 1, the strength of graphite decreases after bonding. During cooling, the residual stress caused by the bonding between graphite and AlN may have lowered the tensile strength of graphite. The average strength and the standard deviation are listed in Table 2. 

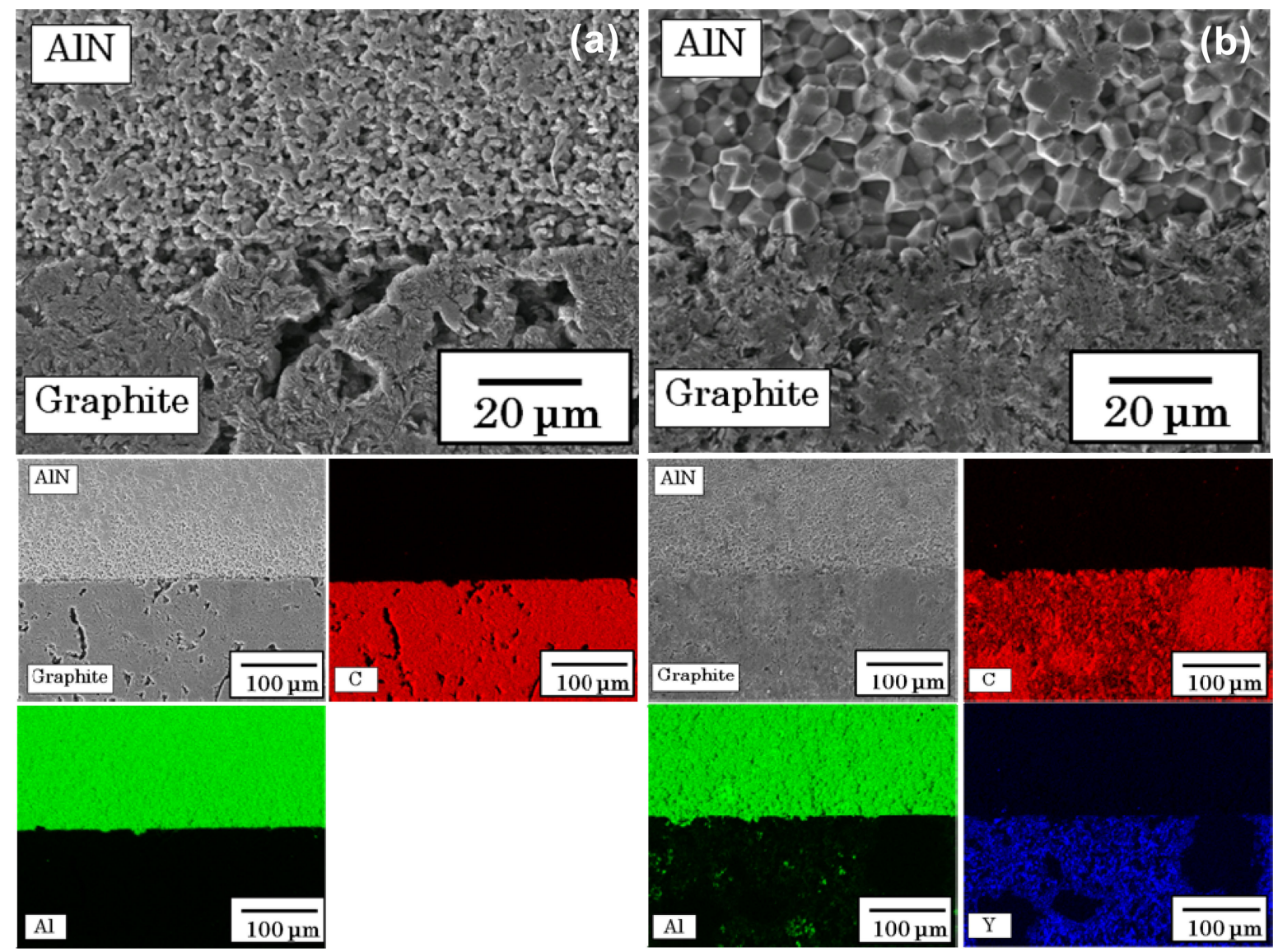

Fig. 8. Cross-sectional SEM images and elemental mapping images of $\mathrm{C}, \mathrm{Al}$, and $\mathrm{Y}$ at the interface of the AlN/graphite samples prepared (a) without $\mathrm{Y}_{2} \mathrm{O}_{3}$, and (b) with 10 mass $\% \mathrm{Y}_{2} \mathrm{O}_{3}$ additive.

Figure 8 shows the interface of AlN/graphite sample without $\mathrm{Y}_{2} \mathrm{O}_{3}$ (a), and that with 10 mass $\% \mathrm{Y}_{2} \mathrm{O}_{3}$ (b). Both samples were prepared at $1900^{\circ} \mathrm{C}$. In the sample without $\mathrm{Y}_{2} \mathrm{O}_{3}$, some gaps are observed at the interface, indicating weak bonding between AlN and graphite. In contrast, no gaps and delaminations are observed at the interface of the sample with 10 mass $\% \mathrm{Y}_{2} \mathrm{O}_{3}$. Large grains are formed in the AlN layer, indicating sintering was completed. In addition, $\mathrm{Y}$ distribution is clearly observed in the graphite by EDS analysis, as seen in Fig. 8(b). The Al-Y-O phase increases with increasing $\mathrm{Y}_{2} \mathrm{O}_{3}$. The molten $\mathrm{Al}-\mathrm{Y}-\mathrm{O}$ phase contributes not only to the densification of AIN, but also to the bonding strength: the $\mathrm{Al}-\mathrm{Y}-\mathrm{O}$ phase fills the pores in graphite and then during cooling, converts to $\mathrm{Al}_{2} \mathrm{Y}_{4} \mathrm{O}_{9}$ phase.

\section{Conclusions}

A strong bond was formed between graphite and AlN by using $\mathrm{Y}_{2} \mathrm{O}_{3}$ as sintering additive at 1800 and $1900^{\circ} \mathrm{C}$ during SPS. No gaps and delaminations were observed at the interface of the AlN/graphite samples. The bonding mechanism is explained as follows: As the temperature increases under pressure, a molten $\mathrm{Al}-\mathrm{Y}-\mathrm{O}$ phase forms and flows into the open pores of graphite. As the material cools, a $\mathrm{Al}_{2} \mathrm{Y}_{4} \mathrm{O}_{9}$ phase forms, resulting in a physical bond between the graphite and AIN. The bonding strength reached $19 \mathrm{MPa}$ at $1900^{\circ} \mathrm{C}$ for the sample containing 10 mass $\% \mathrm{Y}_{2} \mathrm{O}_{3}$. These joints are simple to make and have potential for high-temperature industrial applications.

\section{References}

1) K. Kobayashi, K. Maeda, H. Sano and Y. Uchiyama, Carbon, 33, 397-403 (1995).

2) Q. Zhu, X. Qiu and C. Ma, Carbon, 37, 1475-1484 (1999).

3) D. Zhu, P. Hing, P. Brown and Y. Sahai, J. Mater. Process. Technol., 48, 517-523 (1995).

4) P. Anger, L. G. Yu, K. A. Khor, G. Korb and I. Zalite, J. Eur. Ceram. Soc., 25, 1919-1927 (2005).

5) L. Gao, J. S. Hong, H. Miyamoto and S. D. D. L. Torre, J. Eur. Ceram. Soc., 20, 2149-2152 (2000).

6) W. Li and L. Gao, J. Eur. Ceram. Soc., 20, 2441-2445 (2000).

7) K. A. Khor, L.-G. Yu, S. H. Chan and X. J. Chen, J. Eur. Ceram. Soc., 23, 1855-1863 (2003).

8) G. Xie, O. Ohashi, T. Yoshioka, M. Song, K. Mitsuishi, H. Yasuda, K. Furuya and T. Noda, Mater. Trans., 42, 1846-1849 (2001).

9) H. Kondo, A. Yokohama, M. Omori, A. Ohkubo, T. Hirai, F. Watari, M. Uo and T. Kawasaki, Mater. Trans., 45, 3156-3162 (2004).

10) M. Estili, K. Takagi and A. Kawasaki, Scr. Mater., 59, 703-705 (2008).

11) F. J. M. Haussonne, Mater. Manuf. Process., 10, 717-755 (1995).

12) M. Kasori and F. Ueno, J. Eur. Ceram. Soc., 15, 435-443 (1995). 